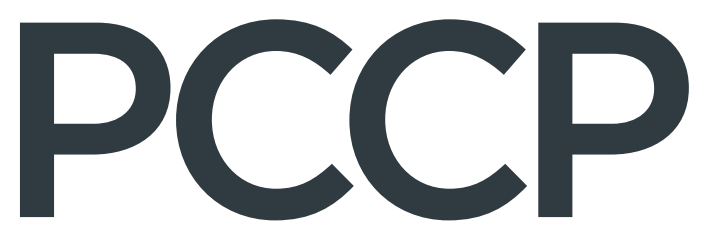

Physical Chemistry Chemical Physics rsc.li/pccp
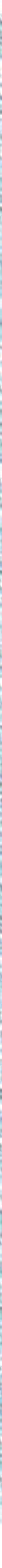

PAPER

ROYAL SOCIETY

Hong Fang, Puru Jena et al.

Super-electrophiles of tri- and tetra-anions stabilized by

selected terminal groups and their role in binding noble

gas atoms

Number

14 October 2021

Pages 21353-22208

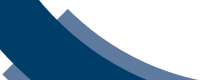

(1) 
Check for updates

Cite this: Phys. Chem. Chem. Phys., 2021, 23, 21496

Received 3rd May 2021,

Accepted 16th July 2021

DOI: $10.1039 / \mathrm{d} 1 \mathrm{cp} 01969 \mathrm{~d}$

rsc.li/pccp

\section{Super-electrophiles of tri- and tetra-anions stabilized by selected terminal groups and their role in binding noble gas atoms $\dagger$}

\begin{abstract}
Ming Min Zhong, $\ddagger^{\mathrm{a}}$ Hong Fang, (D) $\ddagger^{\star^{b}}$ Deepika (D) ${ }^{\mathrm{b}}$ and Puru Jena (D) $\star^{\mathrm{b}}$
Stabilization of multiply-charged atomic clusters in the gas phase has been a topic of great interest not only because of their potential applications as weakly-coordinating anions, but also for their ability to promote unusual reactions and serve as building blocks of materials. Recent experiments have shown that, after removing one terminal ligand from the closo-dodecacyano-borate, $\mathrm{B}_{12}(\mathrm{CN})_{12}{ }^{2-}$, the cluster can strongly bind an argon atom at room temperature. Bearing this in mind, here, we have developed more than a dozen highly stable tri- and tetra-anions using density functional theory (DFT) calculations with hybrid functional (B3LYP) and semi-empirical dispersion corrections. The interactions between the clusters and noble gas atoms, including $\mathrm{Ne}$, Ar and $\mathrm{Kr}$, are studied. The resulting super-electrophilic sites embedded in these charged clusters can bind noble gas atoms with binding energies up to $0.7 \mathrm{eV}$. This study enriches the database of highly-charged clusters and provides a viable design rule for superelectrophiles that can strongly bind noble gas atoms.
\end{abstract}

Stability of multiply-charged negative ions has been a topic of great interest for a long time. ${ }^{1-5}$ While these highly-negative anions can be stabilized in solutions or in matrices protected by solvation shells or counter ions, respectively, they are seldom stable in the gas phase, particularly if their sizes are small. One of the well-known stable gas-phase dianions is closododecaborate, $\mathrm{B}_{12} \mathrm{H}_{12}{ }^{2-}$, whose second electron is bound by $0.9 \mathrm{eV}$. Using density functional theory Zhao et al. ${ }^{6}$ recently showed that the stability of $\mathrm{B}_{12} \mathrm{H}_{12}{ }^{2-}$ can be greatly enhanced by using $\mathrm{CN}$ instead of $\mathrm{H}$ as terminal groups, with the resulting $\mathrm{B}_{12}(\mathrm{CN})_{12}{ }^{2-}$ dianion exhibiting a second electron affinity of $5.3 \mathrm{eV}$. Warneke et al. ${ }^{7}$ had subsequently shown, using both theory and experiment, that the stability of $\mathrm{B}_{12} \mathrm{H}_{12}{ }^{2-}$ can also be enhanced by replacing $\mathrm{H}$ by halogens. Later, Moon et al. ${ }^{8}$ predicted that the second electron affinity of $\mathrm{B}_{12}(\mathrm{CN})_{12}{ }^{2-}$ can be further enhanced by replacing $\mathrm{CN}$ with $\mathrm{BO}$ moieties. The extraordinary stability of $\mathrm{B}_{12}(\mathrm{CN})_{12}{ }^{2-}$ has been recently experimentally confirmed by Mayer et al. ${ }^{9}$ and the measured second electron affinity of $5.5 \mathrm{eV}$ is in good agreement with the calculated value. Zhao et $a l .{ }^{10}$ then showed that stable gas-phase tri-anions can be formed by tailoring the composition of the boron core of the

\footnotetext{
${ }^{a}$ School of Physical Science and Technology, Southwest University, Chongqing 400715, China

${ }^{b}$ Department of Physics, Virginia Commonwealth University, Richmond, VA 23238 ,

USA. E-mail: pjena@vcu.edu, hfangtom@gmail.com

$\dagger$ Electronic supplementary information (ESI) available. See DOI: 10.1039/ d1cp01969d

\$ Co-first authors.
}

dianion. They predicted a stable gas-phase tri-anion, $\mathrm{BeB}_{11}$ $(\mathrm{CN})_{12}{ }^{3-}$, whose third electron is bound by an extraordinarily large value of $2.65 \mathrm{eV}$. Fang and Jena have ${ }^{11}$ prescribed a systematic rule by which small clusters can carry even more extra electrons, forming stable gas-phase tetra- and pentaanions with -4 and -5 charge states, respectively. The above studies clearly established the important role of terminal groups in the stability of highly-charged anions.

Applications of the mono- and di-anions in the synthesis of halogen-free electrolytes for $\mathrm{Li}, \mathrm{Na}$, and $\mathrm{Mg}$ batteries have since been discussed, both theoretically and experimentally. ${ }^{12-14}$ Mayer et $a .^{9}$ have demonstrated yet another important functionality of the di-anions, such as $\mathrm{B}_{12}(\mathrm{CN})_{12}{ }^{2-}$. Upon removal of one $\mathrm{CN}$ moiety from the cluster, they found that the exposed $\mathrm{B}$ atom in the $\mathrm{B}_{12}$ cage becomes electron deficient and positively charged. The exposed $\mathrm{B}$ can then interact with Ar atom through both charge transfer and covalent bonding with a binding energy of $0.61 \mathrm{eV}$. Recently, Meenakshi and Ghanty ${ }^{15,16}$ showed that the use of electronegative ligands as well as replacement of one $\mathrm{B}$ atom by $\mathrm{Be}$ in the cluster can further enhance the binding energy of noble gas atoms. Experiment has been carried out on binding Ne atoms using the same procedure. ${ }^{17}$ Here, by density functional calculations with hybrid functional (B3LYP) and semi-empirical dispersion corrections, we have developed a number of stable tri-anions using a set of linearly configured ligand clusters and found that the species can interact with noble gas atoms $(\mathrm{Ng})$ strongly. 


\section{Design of stable tri- and tetra-anions}

Inspired by the above works and realizing the importance of enlarging the pool of multiply-charged anions, we followed a rational design approach proposed earlier by Fang and Jena ${ }^{11}$ and later by Zhong et al. ${ }^{18}$ and examined their potential to bind noble gas atoms (e.g., Ne, $\mathrm{Ar}$ and $\mathrm{Kr}$ ). It was demonstrated ${ }^{11}$ that the stability of a charged cluster can be measured by the sum $(V)$ of the adiabatic electron affinities $\left(\mathrm{EA}_{i}\right)$ of a cluster with $n$ extra electrons, namely,

$$
V=\sum_{i=1}^{n} \mathrm{EA}_{i},
$$

where

$$
\mathrm{EA}_{i}=E_{i-1}-E_{i}
$$

with $E_{i}$ being the energy of the cluster in the $i$ th-charge state. Note that only a very limited number of clusters are known to be stable as tri-anions so far, including $\mathrm{BeB}_{11}(\mathrm{CN})_{12}{ }^{3-}, \mathrm{BeB}_{11}(\mathrm{SCN})_{12}{ }^{3-}$, $\mathrm{BeB}_{11}(\mathrm{BO})_{12}{ }^{3-}, \quad \mathrm{B}_{12}(\mathrm{CN})_{10}\left(\mathrm{C}_{2}\right)_{2}{ }^{3-}$ and $\mathrm{B}_{12}(\mathrm{CN})_{12}(\mathrm{OBeS})_{2}{ }^{3-} \cdot{ }^{10,11,18}$ Among these, $\mathrm{BeB}_{11}(\mathrm{CN})_{12}{ }^{3-}$ has the highest third electron affinity, $\mathrm{EA}_{3}=2.65 \mathrm{eV}^{8}$ and $\mathrm{B}_{12}(\mathrm{CN})_{10}\left(\mathrm{C}_{2}\right)_{2}{ }^{3-}$ is the smallest stable tri-anion with a radius of $4.85 \AA^{18}{ }^{18}$ It is found that the stability of these charged clusters is determined by their closeness to the closed-shell model (all-paired electrons), the electron affinity of the terminal groups in the structures, and their sizes. ${ }^{11}$ The general prescription for designing highly charged clusters is to assemble them from known stable clusters with lesser charges. We chose mono-anions having large electron affinities as the terminal groups to the boron-cage skeleton whose stability is governed by the WadeMingos rule. ${ }^{19}$ To avoid steric hindrance between the neighboring groups,$^{20}$ these terminal groups are all in linear configurations as shown in Fig. S1 and Table S1 of the ESI. $\dagger$ Each of these ligands has a magnetic moment of $1 \mu_{\mathrm{B}}$ in the ground state, since their closed shell corresponds to a ' -2 ' charge state. Among them, $\mathrm{C}_{2}{ }^{-}$, $\mathrm{SBN}^{-}, \mathrm{OBeO}^{-}, \mathrm{OMgO}^{-}, \mathrm{NB}_{2} \mathrm{~N}^{-}, \mathrm{O}_{3} \mathrm{Be}_{2}^{-}$and $\mathrm{O}_{3} \mathrm{Mg}_{2}{ }^{-}$all have larger $\mathrm{EA}_{1}$ than that of $\mathrm{CN}^{-}(4.10 \mathrm{eV})$. Previously, $\mathrm{CN}^{-}$as the ligand has led to many di-, tri-, tetra- and even penta-anions ${ }^{11}$ with great stability (e.g., $\left.\mathrm{B}_{12}(\mathrm{CN})_{12}{ }^{2-}\right)$. Thus, it is expected that these mono-anions can also form stable gas-phase tri-anions. Super-electrophilic sites that strongly bind noble gas $(\mathrm{Ng})$ atoms can then be created based on the newly developed triand tetra-anions.

We start with $\mathrm{BeB}_{11}(\mathrm{CN})_{12}{ }^{3-}$ and replace one of the $\mathrm{CN}$ moieties with one of the ligands, including $\mathrm{C}_{2}, \mathrm{NB}, \mathrm{O}_{2}$, OS, $\mathrm{S}_{2}, \mathrm{NCN}, \mathrm{NBS}, \mathrm{OBeO}, \mathrm{OBeS}, \mathrm{OMgO}, \mathrm{C}_{2} \mathrm{~S}, \mathrm{SC}_{2} \mathrm{~S}, \mathrm{NB}_{2} \mathrm{~N}$ and $\mathrm{O}_{3} \mathrm{~B}_{2}$, to form new stable tri-anions. The optimized geometries of these tri-anions are given in Fig. 1. Their basic properties such as the molar volume, ionic radius, multiplicity $(M)$, binding energies of successive electrons, $\mathrm{EA}_{i}$, and the total energy gain by adding all the extra electrons, $V(\mathrm{eV})$ are given in Table 1 . For each of them, the ground state configuration is identified
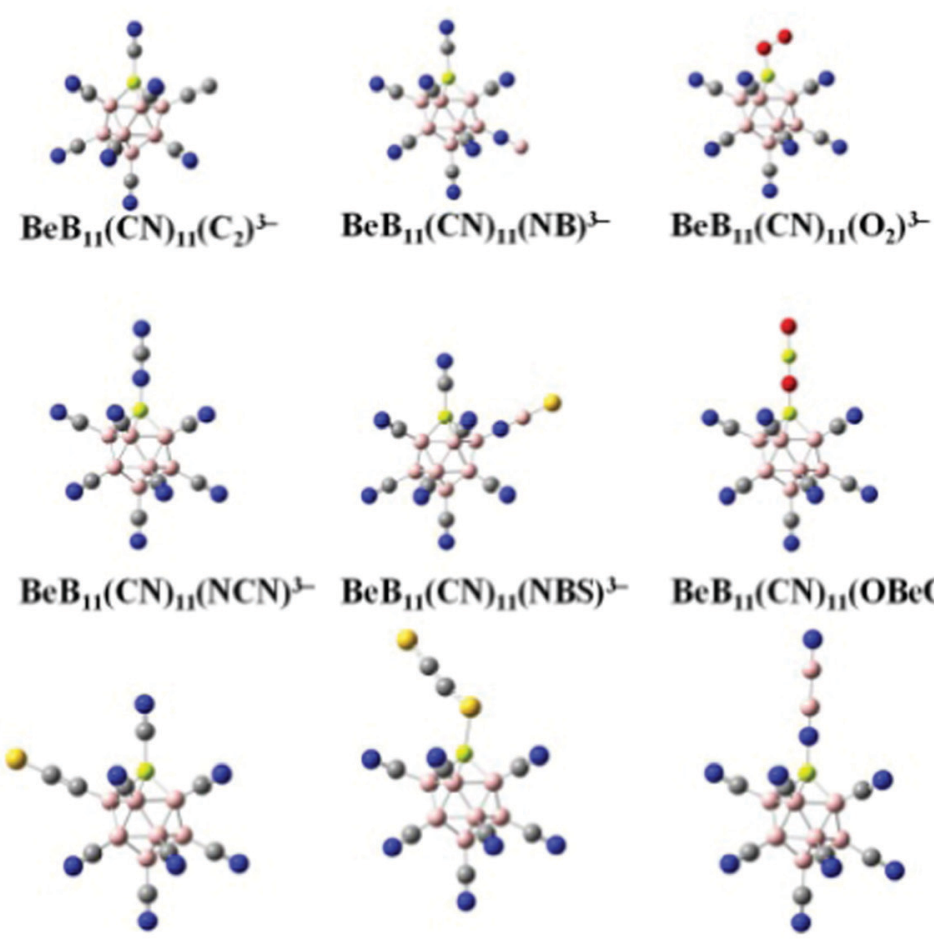

$\mathrm{BeB}_{11}(\mathrm{CN})_{11}\left(\mathrm{C}_{2} \mathrm{~S}\right)^{3-} \mathrm{BeB}_{11}(\mathrm{CN})_{11}\left(\mathrm{SC}_{2} \mathrm{~S}\right)^{3-}$
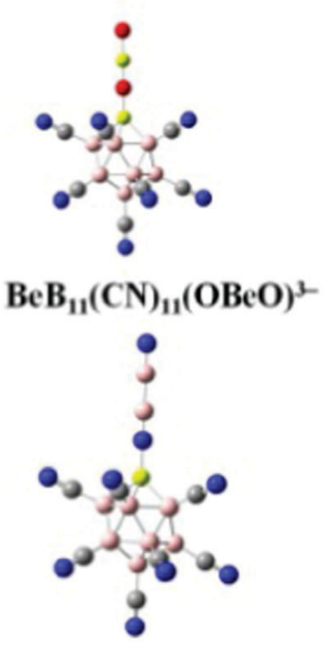

$\mathrm{BeB}_{11}(\mathrm{CN})_{11}\left(\mathrm{NB}_{2} \mathrm{~N}\right)^{3-}$
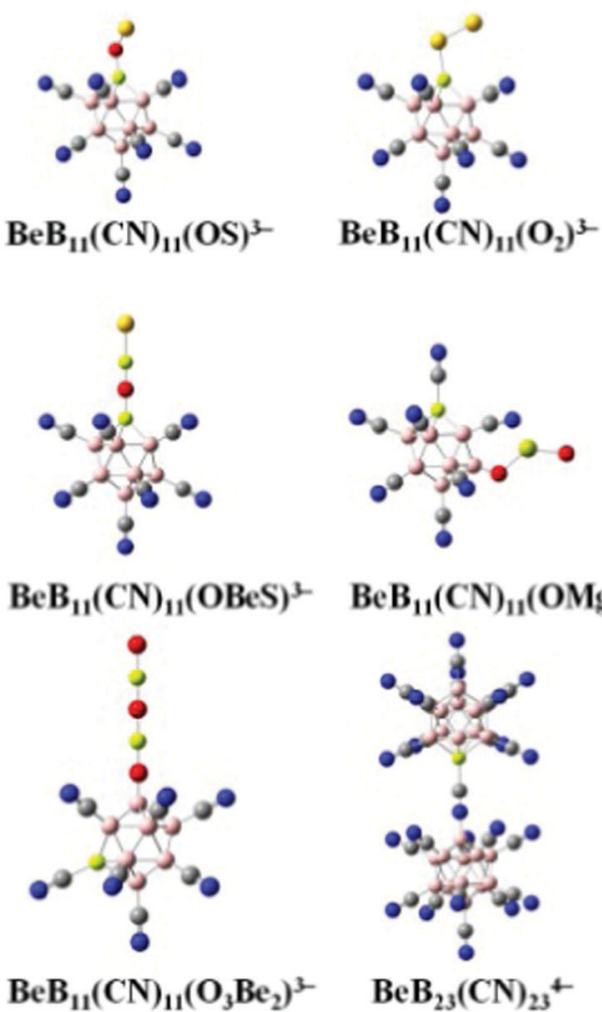

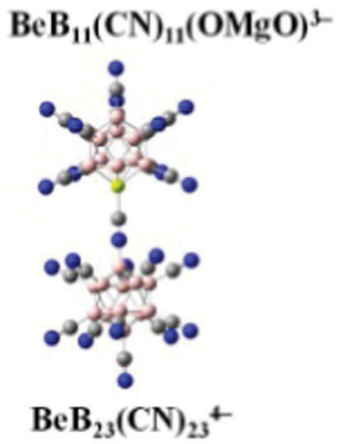

Fig. 1 Optimized structures of the new gas-phase tri-anions that are stabilized by replacing one of the $\mathrm{CN}$ ligands in $\mathrm{BeB}{ }_{11}(\mathrm{CN})_{12}{ }^{3-}$ with selected monoanions shown in Fig. S1 and Table S1 of ESI. $\dagger$ The basic properties of these tri-anions are given in Table 1. Boron atoms are in pink, carbon in grey, nitrogen in blue, beryllium in light yellow, oxygen in red, sulfur in yellow and magnesium in yellow green. 
Table 1 Calculated basic properties, including the molar volume (MV in $\mathrm{cm}^{3} \mathrm{~mol}^{-1}$ ), ionic radius $\left(R\right.$ in $\AA$ ), multiplicity $(M), \mathrm{EA}_{i}(\mathrm{eV})$ and $V(\mathrm{eV})$ value, of the developed stable tri- and tetra-anions in their ground states. Their corresponding optimized structures are shown in Fig. 1. In each case, the ionic radius is estimated as half of the longest dimension of the tri-anion structure. The parameters of the previously known stable tri-anion $\mathrm{BeB}_{11}(\mathrm{CN})_{12}{ }^{3-10}$ are given for comparison. $\mathrm{BeB}_{11}(\mathrm{CN})_{11}(\mathrm{OBeS})^{-}$is found to have a distorted optimized structure compared to its " -3 " charge state, resulting in an abnormally small $E_{2}$ value

\begin{tabular}{|c|c|c|c|c|c|c|c|}
\hline Tri-anion & MV & $R$ & $M$ & $\mathrm{EA}_{1}$ & $\mathrm{EA}_{2}$ & $\mathrm{EA}_{3}$ & $V$ \\
\hline $\mathrm{BeB}_{11}(\mathrm{CN})_{12}{ }^{3-}$ & 317.125 & 6.11 & 1 & 8.44 & 4.76 & 2.65 & 15.85 \\
\hline $\mathrm{BeB}_{11}(\mathrm{CN})_{11}\left(\mathrm{C}_{2}\right)^{3-}$ & 313.16 & 6.11 & 2 & 4.75 & 4.36 & .55 & 9.66 \\
\hline $\mathrm{BeB}_{11}(\mathrm{CN})_{11}(\mathrm{NB})^{3-}$ & 364.04 & 6.11 & 2 & 8.67 & 3.28 & 1.86 & 13.17 \\
\hline $\mathrm{BeB}_{11}(\mathrm{CN})_{11}\left(\mathrm{O}_{2}\right)^{3-}$ & 251.17 & 5.89 & 2 & 7.78 & 4.55 & 1.03 & 13.36 \\
\hline $\mathrm{BeB}_{11}(\mathrm{CN})_{11}(\mathrm{OS})^{3-}$ & 307.94 & 6.24 & 2 & 6.98 & 3.95 & 0.13 & 11.06 \\
\hline $\mathrm{BeB}_{11}(\mathrm{CN})_{11}\left(\mathrm{~S}_{2}\right)^{3-}$ & 398.62 & 6.90 & 2 & 7.70 & 3.99 & 0.50 & 12.19 \\
\hline $\mathrm{BeB}_{11}(\mathrm{CN})_{11}(\mathrm{NCN})^{3-}$ & 324.15 & 6.69 & 2 & 6.03 & 3.85 & 1.31 & 11.19 \\
\hline $\mathrm{BeB}_{11}(\mathrm{CN})_{11}(\mathrm{NBS})^{3-}$ & 369.33 & 6.94 & 2 & 5.61 & 3.98 & 0.58 & 10.17 \\
\hline $\mathrm{BeB}_{11}(\mathrm{CN})_{11}(\mathrm{OBeO})^{3-}$ & 331.34 & 6.83 & 2 & 9.12 & 3.23 & 1.87 & 14.22 \\
\hline $\mathrm{BeB}_{11}(\mathrm{CN})_{11}(\mathrm{OBeS})^{3-}$ & 382.18 & 7.29 & 2 & 11.01 & 0.84 & 1.62 & 13.47 \\
\hline $\mathrm{BeB}_{11}(\mathrm{CN})_{11}(\mathrm{OMgO})^{3-}$ & 325.84 & 6.71 & 2 & 9.09 & 2.83 & 2.40 & 14.32 \\
\hline $\mathrm{BeB}_{11}(\mathrm{CN})_{11}\left(\mathrm{C}_{2} \mathrm{~S}\right)^{3-}$ & 250.01 & 6.92 & 2 & 7.64 & 3.77 & 0.60 & 12.01 \\
\hline $\mathrm{BeB}_{11}(\mathrm{CN})_{11}\left(\mathrm{SC}_{2} \mathrm{~S}\right)^{3-}$ & 366.61 & 7.54 & 2 & 7.42 & 3.93 & 0.61 & 11.96 \\
\hline \multirow{2}{*}{$\begin{array}{l}\mathrm{BeB}_{11}(\mathrm{CN})_{11}\left(\mathrm{NB}_{2} \mathrm{~N}\right)^{3-} \\
\mathrm{BeB}_{11}(\mathrm{CN})_{11}\left(\mathrm{O}_{3} \mathrm{Be}_{2}\right)^{3-}\end{array}$} & 410.55 & 7.55 & 2 & 8.61 & 3.80 & 1.76 & 14.17 \\
\hline & 322.39 & 8.04 & 2 & 9.30 & 3.17 & 2.16 & 14.63 \\
\hline Tet & $R$ & $M$ & $H_{1}$ & $\mathrm{EA}_{2}$ & $5 \times 3$ & $\mathrm{EA}_{4}$ & $V$ \\
\hline (1) $23(-1)_{23}$ & 3.028 & 2 & 0.10 & 0.02 & 4.08 & 0.94 & 20.44 \\
\hline
\end{tabular}

by comparing the energies of all possible structural isomers with non-equivalent $\mathrm{CN}$ ligand relative to the Be site substituted by the linear mono-anion, as shown in Table S2 of ESI. $\dagger$ No general rule is found to identify which site is preferred for the ground state. Previously, there were only 5 stable gas-phase tri-anions that have been reported. These include $\mathrm{BeB}_{11}(\mathrm{CN})_{12}{ }^{3-}$, $\mathrm{BeB}_{11}(\mathrm{BO})_{12}{ }^{3-}$ and $\mathrm{BeB}_{11}(\mathrm{SCN})_{12}{ }^{3-}$ whose $\mathrm{EA}_{3}$ are $2.65,1.30$ and $0.59 \mathrm{eV}$, respectively. ${ }^{10}$ In addition, two stable tri-anions without beryllium (Be) insertion into the boron cage were also found in the previous study, including $\mathrm{B}_{12}(\mathrm{CN})_{10}\left(\mathrm{C}_{2}\right)_{2}{ }^{3-}$ and $\mathrm{B}_{12}(\mathrm{CN})_{10}(\mathrm{OBeS})_{2}{ }^{3-}$ with $\mathrm{EA}_{3}$ of 0.92 and $1.43 \mathrm{eV}$, respectively. ${ }^{18}$ Compared to these, the new stable tri-anions in the current study all show $1 \mu_{\mathrm{B}}$ magnetic moment in their ground states and have similar sizes as well as similar values of $\mathrm{EA}_{3}$. Among them, $\mathrm{BeB}_{11}(\mathrm{CN})_{11}(\mathrm{OMgO})^{3-}$ and $\mathrm{BeB}_{11}(\mathrm{CN})_{11}\left(\mathrm{O}_{3} \mathrm{Be}_{2}\right)^{3-}$ exhibit the largest $\mathrm{EA}_{3}$ values of 2.40 and $2.16 \mathrm{eV}$, respectively, which are comparable to that of $\mathrm{BeB}_{11}(\mathrm{CN})_{12}{ }^{3-}$. It is noted that, whenever p-electrons are involved in the bonding, the terminal groups become tilted when attached to the boron site. ${ }^{12}$

Besides the stable tri-anions, a stable gas-phase tetra-anion $\mathrm{BeB}_{23}(\mathrm{CN})_{23}{ }^{4-}$ is also developed. As demonstrated by Fang and Jena, it is possible to stabilize a tetra-anion by assembling a stable mono-anion and a stable tri-anion. ${ }^{11}$ First, removal of one $\mathrm{CN}$ ligand from the stable di-anion $\mathrm{B}_{12}(\mathrm{CN})_{12}{ }^{2-}$ results in a stable mono-anion, $\mathrm{B}_{12}(\mathrm{CN})_{11}{ }^{-}$, with an $\mathrm{EA}_{1}$ value of $8.49 \mathrm{eV}$. Combining this to the known tri-anion $\mathrm{BeB}_{11}(\mathrm{CN})_{12}{ }^{3-}$, the tetraanion $\mathrm{BeB}_{23}(\mathrm{CN})_{23}{ }^{4-}$ is formed as shown in Fig. 2. The basic properties of this tetra-anion are given in Table 1. It has a large $\mathrm{EA}_{4}$ value of $0.94 \mathrm{eV}$, only second to the tetra-anion $\mathrm{Be}_{2} \mathrm{~B}_{22}(\mathrm{CN})_{23}{ }^{4-}$ which has the highest $\mathrm{EA}_{4}$ value of $1.48 \mathrm{eV}^{11}$ known so far.

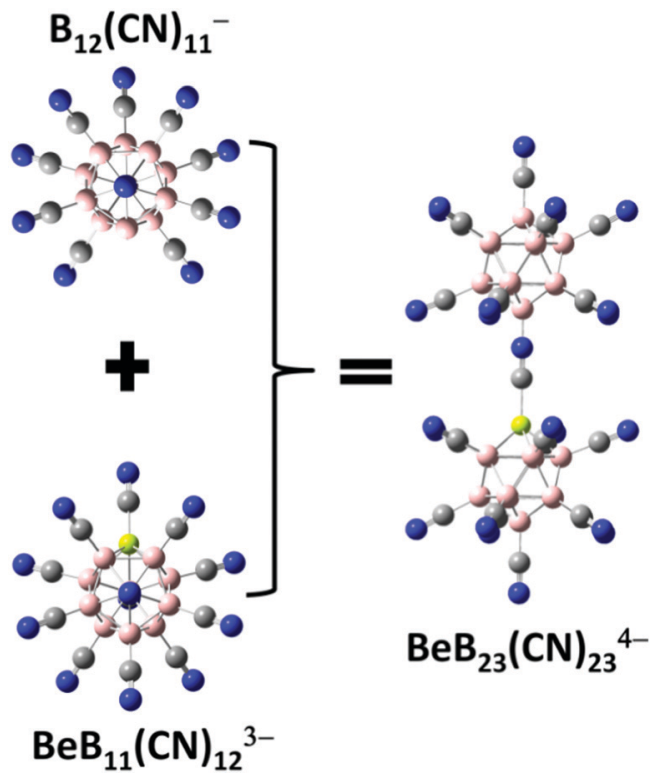

Fig. 2 Optimized structure of the new stable gas-phase tetra-anion $\mathrm{BeB}_{23}(\mathrm{CN})_{23}{ }^{4-}$ that is developed by assembling a known mono-anion $\mathrm{B}_{12}(\mathrm{CN})_{11}{ }^{-}$and a tri-anion $\mathrm{BeB}_{11}(\mathrm{CN})_{12}{ }^{3-}$. Boron atoms are in pink, beryllium in light yellow, carbon in grey, and nitrogen in blue.

The results of tri- and tetra-anions in Table 1 can be well described by a phenomenological model in which each additional electron is in a bound state of a general 3D potential well. ${ }^{11}$ According to this model, the key quantities to stabilize a multiply-charged cluster are the $V$ value and the cluster radius $(r)$. A plot of $V v s .1 / r^{2}$ for the studied clusters is given in Fig. 3, showing that the all the data points associated with the tri- and tetra-anions lie above a threshold line

$$
V_{n}=a_{n} / r^{2}+V_{0}
$$

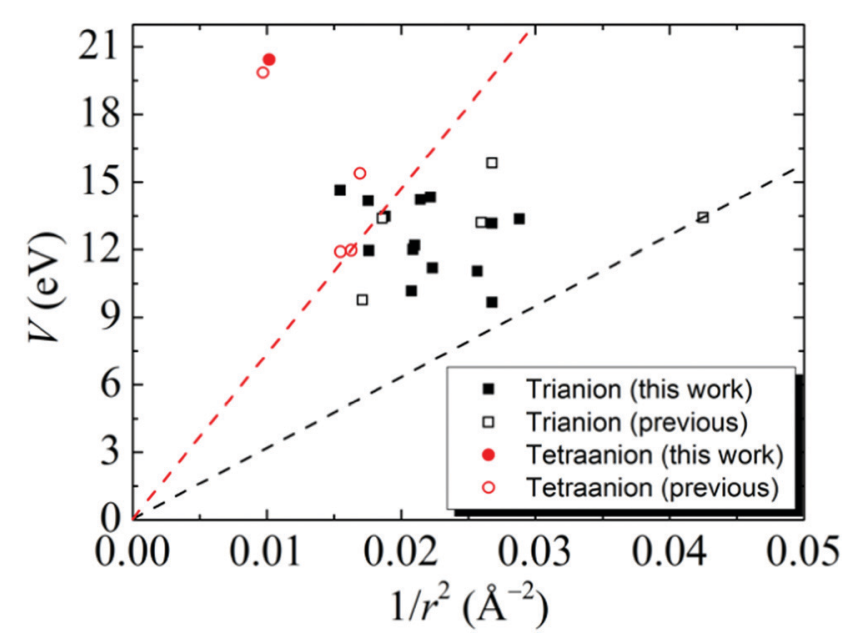

Fig. 3 Calculated $V$ vs. $1 / r^{2}$ data (eqn (1)) for the stable gas-phase tri(black) and tetra- (red) anions developed in this study (solid square) and from previous studies in ref. 11 (open square). The threshold lines (eqn (3)) for the tri- (black dashed line) and tetra- (red dashed line) anions are given. 
where $n=3$ and 4 for tri- and tetra-anions, respectively. The threshold line (black dashed line in Fig. 3) of the tri-anions is determined by $\mathrm{B}_{12} \mathrm{H}_{10}\left(\mathrm{C}_{2}\right)_{2}{ }^{3-}$ which holds the record as the smallest stable tri-anion known so far. ${ }^{18}$ The threshold line (red dashed line in Fig. 3) of tetra-anions is determined by $\mathrm{BeB}_{11}(\mathrm{CN})_{11} \mathrm{Sr}(\mathrm{CN})_{4}{ }^{4-}{ }^{11}$ This suggests that all the newlydeveloped multiply-charged clusters adhere to the general potential model.

\section{Binding of noble gas atoms to electrophilic sites in multiply charged anions}

Earlier studies have shown that the mono-anion $\mathrm{B}_{12}(\mathrm{CN})_{11}{ }^{-}$is a super-electrophilic cluster. Upon removal of one $\mathrm{CN}$ ligand from $\mathrm{B}_{12}(\mathrm{CN})_{12}{ }^{2-}$, the exposed $\mathrm{B}$ atom becomes electron deficient and binds strongly to Ar. ${ }^{9}$ Further research has shown that more super-electrophilic clusters can be developed by replacing one of the B atoms in the core by a Be atom as well as using other multiply charged clusters. ${ }^{15-17}$ These highly charged clusters are often formed by terminal ligands with large EA values. When a ligand is removed, the exposed boron or beryllium site in the cluster becomes highly electron deficient and can, therefore, bind $\mathrm{Ng}$ atoms strongly via chemical bonding.

We have studied the potential of the newly developed tri- and tetra-anions to bind $\mathrm{Ng}$ atoms. For demonstration, we chose the tetra-anion $\mathrm{BeB}_{23}(\mathrm{CN})_{23}{ }^{4-}$ and the tri-anion $\mathrm{BeB}_{11}(\mathrm{CN})_{11}(\mathrm{OMgO})^{3-}$ which has the largest $\mathrm{EA}_{3}$ value of all the tri-anions in this study. After removing one $\mathrm{CN}$ ligand from $\mathrm{BeB}_{11}(\mathrm{CN})_{11}(\mathrm{OMgO})^{3-}$, the ground-state of $\mathrm{BeB}_{11}(\mathrm{CN})_{10}(\mathrm{OMgO})^{2-}$ is the one in which the $\mathrm{Be}$ site is exposed (see Fig. S2A of ESI $\dagger$ ). Fig. 4A shows the optimized structures of the ground states $\left[\mathrm{BeB}_{11}(\mathrm{CN})_{10}(\mathrm{OMgO})-\mathrm{Ng}\right]^{2-}(\mathrm{Ng}=$ $\mathrm{Ne}, \mathrm{Ar}, \mathrm{Kr}$ ). As given in Table 2, the exposed Be site is highly electron-deficient. There is significant charge transfer from the $\mathrm{Ng}$ atoms to the cluster when the two binds. The ground-state configuration of $\mathrm{BeB}_{23}(\mathrm{CN})_{22}{ }^{3-}$ corresponds to the one in which the $\mathrm{B}$ site adjacent to Be is exposed (see Fig. S2B of ESI $\dagger$ ). The optimized structures of $\left[\mathrm{BeB}_{23}(\mathrm{CN})_{22}-\mathrm{Ng}\right]^{3-}(\mathrm{Ng}=\mathrm{Ne}, \mathrm{Ar}$, $\mathrm{Kr}$ ) are shown in Fig. 4B. As listed in Table 2, there is also significant charge transfer from the $\mathrm{Ng}$ atoms to the cluster when the two binds. The charge transfer of $0.34 e$ out of $\mathrm{Ar}$ is comparable to that $(0.41 e)$ in the case of $\left[\mathrm{B}_{12}(\mathrm{CN})_{11}-\mathrm{Ar}\right]^{-} .{ }^{9}$ The binding energies between the $\mathrm{Be}$ site and the $\mathrm{Ng}$ atoms are considered quite large, especially for the case of $\left[\mathrm{BeB}_{23}(\mathrm{CN})_{22}-\mathrm{Ng}\right]^{3-}$, where the binding energies are higher than those in the case of $\left[\mathrm{BeB}_{11}(\mathrm{CN})_{11}-\mathrm{Ng}\right]^{2-},{ }^{17}$ as shown in Table 2.

To understand the nature of the chemical bonding between $\mathrm{Ng}$ and the cluster, we conducted energy decomposition analysis on $\mathrm{Ar}-\mathrm{Be}$ in $\left[\mathrm{BeB}_{11}(\mathrm{CN})_{10}(\mathrm{OMgO})-\mathrm{Ar}\right]^{2-}$. It is found that, out of the total interaction energy of $\Delta E\left(-3.42 \mathrm{kcal} \mathrm{mol}^{-1}\right)$, the repulsion $\left(\Delta E^{\mathrm{rep}}=29.52 \mathrm{kcal} \mathrm{mol}^{-1}\right)$ and polarization $\left(\Delta E^{\mathrm{pol}}=\right.$ $\left.-13.03 \mathrm{kcal} \mathrm{mol}^{-1}\right)$ terms are dominant, indicating increasing orbital overlap as well as significant changes in the orbital shape when Ar interacts with Be in the cluster. The dispersion energy
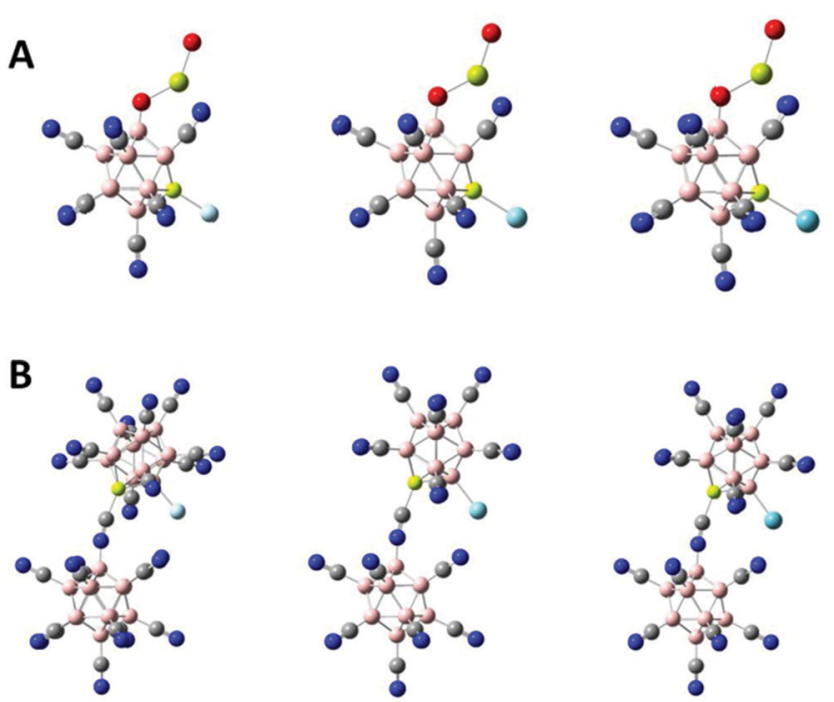

Fig. 4 Optimized ground-state structures of $(\mathrm{A})\left[\mathrm{BeB}_{11}(\mathrm{CN})_{10}(\mathrm{OMgO})-\right.$ $\mathrm{Ng}^{2-}$ and $(\mathrm{B})\left[\mathrm{BeB}_{23}(\mathrm{CN})_{22}-\mathrm{Ng}\right]^{3-}$ with $\mathrm{Ng}=\mathrm{Ne}$, Ar and $\mathrm{Kr}$ from left to right. Boron atom are in pink, carbon in grey, nitrogen in blue, beryllium in light yellow, oxygen in red, magnesium in green yellow and $\mathrm{Ng}$ atoms in light blue.

Table 2 Calculated binding parameters between the di-anion $\mathrm{BeB}_{11}(\mathrm{CN})_{10}$ $(\mathrm{OMgO})^{2-}$ and the noble gas $(\mathrm{Ng})$ atoms, including the bond length (BL) between $\mathrm{Ng}$ and the exposed $\mathrm{Be}$, the charge state of $\mathrm{Be}$, the charge transfer (e) out of the $\mathrm{Ng}$ atom and the binding energy (BE) between the $\mathrm{Be}$ site and the $\mathrm{Ng}$ atom. For comparison, in each case of $\left[\mathrm{BeB}_{23}(\mathrm{CN})_{22}-\mathrm{Ng}\right]^{3-}$ $(\mathrm{Ng}=\mathrm{Ne}, \mathrm{Ar}, \mathrm{Kr})$, the binding energy in the parenthesis corresponds to the case of $\left[\mathrm{BeB}_{11}(\mathrm{CN})_{11}-\mathrm{Ng}\right]^{2-15}$

\begin{tabular}{lllll}
\hline & $\mathrm{BL}(\AA)$ & $q_{\mathrm{Be}}$ & $q_{\mathrm{Ng}}$ & $\mathrm{BE}(\mathrm{eV})$ \\
\hline$\left[\mathrm{BeB}_{11}(\mathrm{CN})_{10}(\mathrm{OMgO})-\mathrm{Ng}\right]^{2-}$ & & & \\
$\mathrm{Ne}$ & 1.942 & 1.051 & 0.106 & 0.14 \\
$\mathrm{Ar}$ & 2.177 & 0.853 & 0.264 & 0.22 \\
$\mathrm{Kr}$ & 2.258 & 0.755 & 0.346 & 0.27 \\
& & & & \\
{$\left[\mathrm{BeB}_{23}(\mathrm{CN})_{22}-\mathrm{Ng}\right]^{3-}$} & & & $0.40(0.14)$ \\
$\mathrm{Ne}$ & 2.003 & 0.433 & 0.114 & $0.59(0.47)$ \\
$\mathrm{Ar}$ & 2.166 & 0.185 & 0.343 & $0.71(0.57)$ \\
$\mathrm{Kr}$ & 2.193 & 0.024 & 0.489 &
\end{tabular}

$\left(\Delta E^{\text {disp }}=-5.17 \mathrm{kcal} \mathrm{mol}^{-1}\right)$ also contributes significantly to the total interaction energy. Thus, the Ar-Be interaction can be characterized as a mixture of ionic and covalent bonding as well as the interaction between polarized electron clouds, which is similar to the cases of $\left[\mathrm{BeB}_{11}(\mathrm{CN})_{11} \mathrm{Ng}\right]^{2-}$ dianions. ${ }^{15}$ Although the energy decomposition analysis of $\mathrm{Ar}-\mathrm{B}$ in $\left[\mathrm{BeB}_{23}(\mathrm{CN})_{22}-\mathrm{Ar}\right]^{3-}$ is computationally prohibitive due to its large size, it is expected that chemical bonding will have a similar nature as found in the above cases.

In conclusion, using a set of stable mono-anions with linear configuration as the terminal groups in boron-based polyhedral clusters, we have developed more than a dozen of tri-anions (in the " -3 " charge state) with compact sizes that are stable in the gas phase. In addition, a stable gas-phase tetra-anion (in the "-4" charge state) is also found by assembling one 
stable mono-anion together with another stable tri-anion. It is found that the relationship between the electron-holding ability of these tri- and tetra-anions (quantified by $V$ in eqn (1)) and their sizes (quantified by their radii) are consistent with the phenomenological model of electronic bound states in a general 3D potential well. ${ }^{11}$ Further studies show that these stable clusters can serve as super-electrophiles, strongly interacting with noble gas atoms via chemical bonding.

\section{Methods}

The calculations are carried out using density functional theory (DFT) with the B3LYP hybrid exchange-correlation functional. ${ }^{21,22}$ We used the Gaussian 03 with $6-31+G(d, p)$ basis sets for all atoms. $^{23}$ Although DFT with standard basis sets has been commonly used to calculate electron affinities for anions, it can suffer from the self-interaction error due to the use of approximate exchange functionals. ${ }^{24,25}$ Being a hybrid functional with empirical parameters, the B3LYP functional used here can cancel some selfinteraction error and has shown relatively small mean absolute errors $(<0.1 \mathrm{eV})$ in the calculated adiabatic electron affinities of anions. $^{25}$ The exchange-correlation energy functional and basis sets used in this paper have been proven to be capable of providing reliable results in previous works. ${ }^{6,10,11}$ Moreover, some theoretical results have been validated by experimental study. ${ }^{9,13,14}$ Dispersive interactions are considered in all calculations using the D3 version of Grimme's dispersion with the original D3 damping function. ${ }^{26}$ In all cases, structures are fully optimized without any symmetry constraints. All considered structures have real vibrational frequencies and, therefore, correspond to the minima in the potential energy surface. The charge analysis is carried out using the natural bond orbital (NBO) method in each case. The energy decomposition analysis based on localized molecular orbitals is carried out using the method in ref. 27 with DFT and the same basis sets. The optimized geometries of the two clusters that can bind strongly with $\mathrm{Ng}$ are given in Tables S3 and S4 in the ESI. $\dagger$ Other data are available upon request.

\section{Conflicts of interest}

There are no conflicts to declare.

\section{Acknowledgements}

This work was supported by the National Natural Science Foundation of China (No. 11504301), Fundamental Research Funds for the Central Universities (XDJK2019 C108). P. J. acknowledges support of the U.S. DOE, Office of Basic Energy Sciences, Division of Material Sciences and Engineering under Award No. DE-FG02-96ER45579.

\section{References}

1 A. Dreuw and L. S. Cederbaum, Chem. Rev., 2002, 102, 181-200.
2 A. A. Tuinman and R. N. Compton, J. Phys. Chem. A, 1998, 102, 9791-9796.

3 N. Zint, A. Dreuw and L. S. Cederbaum, J. Am. Chem. Soc., 2002, 124, 4910-4917.

4 W. B. Wang, A. P. Sergeeva, X. P. Xing, M. Massaouti, T. Karpuschkin, O. Hampe, A. I. Boldyrev, M. M. Kappes and L. S. Wang, J. Am. Chem. Soc., 2009, 131, 9836-9842.

5 L. S. Wang and X. B. Wang, J. Phys. Chem. A, 2000, 104, 1978-1990.

6 H. Zhao, J. Zhou and P. Jena, Angew. Chem., 2016, 128, 3768-3772.

7 J. Warneke, G. L. Hou, E. Apra, C. Jenne, Z. Yang, Z. Qin, K. Kowalski, X. B. Wang and S. S. Xantheas, J. Am. Chem. Soc., 2017, 139, 14749-14756.

8 J. Moon, H. Baek and J. Kim, Chem. Phys. Lett., 2018, 698, 72-76.

9 M. Mayera, V. Lessen, M. Rohdenburg, G. L. Hou, Z. Yang, R. M. Exner, E. Apràe, V. A. Azov, S. Grabowsky, S. S. Xantheas, K. R. Asmisa, X. B. Wang, C. Jenne and J. Warneke, Proc. Natl. Acad. Sci. U. S. A., 2019, 116, 8167-8172.

10 T. Zhao, J. Zhou, Q. Wang and P. Jena, Angew. Chem., 2017, 129, 13606-13610.

11 H. Fang and P. Jena, Angew. Chem., Int. Ed., 2019, 58, 11248-11252.

12 H. Fang and P. Jena, J. Phys. Chem. C, 2017, 121, 7697-7702.

13 T. J. Carter, R. Mohtadi, T. S. Arthur, F. Mizuno, R. Zhang, S. Shirai and J. W. Kampf, Angew. Chem., 2014, 126, 3237-3241.

14 O. Tutusaus, R. Mohtadi, T. S. Arthur, F. Mizuno, E. G. Nelson and Y. V. Sevryugina, Angew. Chem., Int. Ed., 2015, 54, 7900-7904.

15 K. Meenakshi and T. K. Ghanty, Chem. Commun., 2019, 55, 14379-14382.

16 K. Meenakshi and T. K. Ghanty, Phys. Chem. Chem. Phys., 2020, 22, 13368-13372.

17 M. Martin, R. Markus, L. Valentin van, C. N. Marc, G. Simon, R. A. Kunt, J. Carsten and W. Jonas, Chem. Commun., 2020, 56, 4591-4594.

18 M. Zhong, H. Fang and P. Jena, Phys. Chem. Chem. Phys., 2020, 22, 4880-4883.

19 D. M. P. A. Mingos, Nat. Phys. Sci., 1972, 236, 99-102.

20 A. I. Boldyrev and J. Simons, J. Chem. Phys., 1993, 98, 4745-4752.

21 A. Becke, J. Chem. Phys., 1993, 98, 5648-5652.

22 C. Lee, W. Yang and R. G. Parr, Phys. Rev. B: Condens. Matter Mater. Phys., 1998, 37, 785-788.

23 M. J. Frisch, et al., Gaussian 03, Gaussian, Inc., Wallingford CT, 2004.

24 M.-C. Kim, E. Sim and K. Burke, Communication: Avoiding unbound anions in density functional calculations, J. Chem. Phys., 2011, 134, 171103.

25 O. A. Vydrov and G. E. Scuseria, Ionization potentials and electron affinities in the Perdew-Zunger self-interaction corrected densityfunctional theory, J. Chem. Phys., 2005, 122, 184107.

26 S. Grimme, J. Antony, S. Ehrlich and H. Krieg, J. Chem. Phys., 2010, 132, 154104.

27 P. Su and H. Li, J. Chem. Phys., 2009, 131, 014102. 